\title{
filosofar com as crianças: um trabalho sobre o excesso das palavras
}

\author{
beatriz fabiana olarieta ${ }^{1}$ \\ universidade do estado do rio de janeiro - brasil
}

resumo

Filosofar com as crianças e as professoras na escola consiste basicamente em conversar com elas, em perguntar-nos e explorar em forma coletiva os sentidos que o mundo nos apresenta ou nos nega. De outro modo, poderíamos dizer que a prática do filosofar implica um trabalho com e a partir da linguagem. Foucault convidava a considerar a filosofia como um exercício de si no pensamento. Esse exercício implica um exercício de si na linguagem, com a linguagem e a partir da linguagem. A linguagem é nosso modo de habitar o mundo. Por isso, trabalhar com as palavras não é um mero exercício técnico gramatical ou sintático. Perceber as palavras com que nomeamos o mundo, explorá-las, aproximá-las ou afastá-las de outras, deixar nascer novas combinações entre elas, etc. permite que nosso mundo (esse que para cada um de nós se apresenta como "o mundo") também entre em exercício e possa transformar-se, abrir-se a novas possibilidades. Conversar é um modo de colocar em exercício nosso mundo, de pensá-lo. Esse exercício, aparentemente simples, supõe mais do que uma destreza técnica ou o desdobramento de metodologias. Demanda um trabalho sobre o limite da linguagem e implica um trabalho permanente sobre certa capacidade de perceber aquilo que habita nas palavras e que, ao mesmo tempo, escapa delas. Alejandra Pizarnik, Michel Foucault e Pierre Alféri oferecem pistas para poder explorar essa dimensão da linguagem.

palavras-chave: filosofia com crianças; linguagem; foucault; alféri.

\section{filosofar con niños: un trabajo sobre el exceso de las palabras}

resumen

Filosofar con los niños y las maestras en la escuela consiste, básicamente, en conversar, en preguntarnos y explorar en forma colectiva los sentidos que el mundo nos presenta o nos niega. De otro modo, podríamos decir que la práctica del filosofar implica un trabajo con y a partir del lenguaje. Foucault invitaba a considerar la filosofía como un ejercicio de sí en el pensamiento. Ese ejercicio implica un ejercicio de sí en el lenguaje, con el lenguaje y a partir del lenguaje. El lenguaje es nuestro modo de habitar el mundo. Por eso, trabajar con las palabras no es un mero ejercicio técnico gramatical o sintáctico. Percibir las palabras con las que nombramos el mundo, explorarlas, aproximarlas o alejarlas de otras, dejar nacer nuevas combinaciones entre ellas, etc. permite que nuestro mundo (ese que para cada uno de nosotros se presenta como "el mundo") también entre en ejercicio y pueda transformarse, abrirse a nuevas posibilidades. Conversar es un modo de poner en ejercicio nuestro mundo, de pensarlo. Ese ejercicio, aparentemente simple, supone más que una destreza técnica o el despliegue de metodologías. Demanda un trabajo sobre el límite del lenguaje e implica un trabajo permanente sobre cierta capacidad de percibir aquello que habita en las palabras y que, al mismo tiempo, les escapa. Alejandra Pizarnik, Michel Foucault e Pierre Alféri ofrecen pistas para poder explorar esa dimensión del lenguaje.

palabras clave: filosofía con niños; lenguaje; Foucault; alféri.

\footnotetext{
${ }^{1}$ E-mail: olarietaf@hotmail.com
} 


\section{to philosophize with children: a work on the excess of words}

To philosophize with the children and teachers at school is basically to talk to them, to ask ourselves and to explore in a collective way the senses that the world presents or denies us. Otherwise, we could say that the practice of philosophizing implies working with and from language. Foucault invited to consider philosophy as an exercise of self in thought. This exercise implies an exercise of self in language, with language and from language. Language is our way of inhabiting the world. Therefore, working with words is not a mere technical or grammatical exercise. To perceive the words with which we name the world, to explore them, to bring them closer or to separate them from others, to let new combinations be born among them, and so on, allows our world (which for each of us presents itself as "the world") also to exercise and to transform itself, to open itself to new possibilities. Talking is a way of putting our world into practice, of thinking about it. This seemingly simple exercise presupposes more than a technical dexterity or the unfolding of methodologies. It demands a work on the limit of language and implies a permanent work on a certain capacity to perceive what dwells in words and, at the same time, escapes them. Alejandra Pizarnik, Michel Foucault and Pierre Alféri offer clues to explore this dimension of language.

keywords: philosophy with children; language; foucault; alféri. 
filosofar com as crianças: um trabalho sobre o excesso das palavras

Poderíamos dizer que filosofar com as crianças e as professoras na escola consiste basicamente em conversar com elas, em perguntar-nos e explorar em forma coletiva os sentidos que o mundo nos apresenta ou nos nega. De outro modo, poderíamos dizer que a prática do filosofar implica um trabalho com e a partir da linguagem.

A linguagem é nosso modo de habitar o mundo. Por isso, trabalhar com as palavras não é um mero exercício técnico, gramatical ou sintático. Perceber as palavras com que nomeamos aquilo que somos e tudo o que nos rodeia, explorálas, aproximá-las ou afastá-las de outras, deixar nascer novas combinações entre elas, etc. permite que nosso mundo (esse que para cada um de nós se apresenta como "o mundo") também entre em exercício e possa transformar-se, abrir-se a novas possibilidades. Conversar é um modo de colocar em exercício nosso mundo, de pensá-lo.

Mas não é qualquer conversação que permite ou que se abre ao pensar. Conversar muitas vezes não é mais do que a repetição do já sabido, um lugar conhecido, um nadar entre palavras já pronunciadas que nada nos dizem, que só chegam para confirmar o que pensamos saber e que só permitem estabelecer com o mundo uma relação mecânica e totalmente desvitalizada (Cf. LARROSA, 2015).

Foucault (1984) convidava a considerar a filosofia como um exercício de si no pensamento. Esse exercício demanda um exercício de si na linguagem, com ela e a partir dela.

Encontrar-se para pensar com os meninos e as meninas na escola sobre os assuntos mais diversos permite o privilégio de presenciar esforços como o de Matheus buscando junto a seus colegas palavras que the permitam compreender a imagem que lhes devolve um espelho: "Não, não, não! A imagem do espelho não está nem viva nem morta, porque o espelho é uma alma sem coração". 
As palavras de Matheus guardam uma instigante potência. Este texto é uma tentativa de acompanhá-las, de deixar que elas nos mostrem algo dessa zona em que a linguagem se coloca e nos coloca em exercício na hora de filosofar na escola.

\section{o que dizem as palavras... mais e outra coisa}

Começo esta tentativa de entregar-me às palavras de Matheus com três versos de uma poeta argentina, Alejandra Pizarnik:

\section{hablo}

sabiendo que no se trata de eso

siempre no se trata de eso ${ }^{2}$ (PIZARNIK, 2000, p. 400)

Pretendo que esses versos ecoem tanto na possibilidade de pensar a prática da filosofia com crianças quanto no ato da minha própria escrita.

Para alguém que participa de um exercício que poderia resumir-se na palavra conversar, os versos de Pizarnik não podem deixar de provocar certa inquietação. Eles parecem ameaçar o sentido que esse exercício poderia ter. Por que destinar tempo e esforço para abrir espaços onde possamos conversar? Por que ou para que falaríamos com as crianças na escola se sabemos que "sempre não se trata disso"?

Mas, se deixamos ecoar mais um pouco os versos da poeta, talvez seja possível considerar que eles, mais do que anular o sentido da conversa, estão sinalizando sua condição de possibilidade. Ou seja, porque as palavras nunca conseguem esgotar o que mundo é, porque "sempre não se trata" do que elas pretendem dizer, porque (como também diz Pizarnik) “[...] cada palabra dice lo que dice y además más y otra cosa"3 (PIZARNIK, 2000, p. 283) é que podemos conversar, é que faz sentido conversar.

Se existissem palavras certas capazes de esgotar os sentidos do mundo (do certo e do errado, do bem e do mal, do verdadeiro e do falso, do dentro e do fora, do correto e do incorreto, do belo e do feio, etc.), conversar não valeria a pena. Seria suficiente escutar aos que dominam essas palavras e aceitá-las ou aprendêlas. No máximo o que poderíamos aspirar seria a dominar as habilidades que

\footnotetext{
2 falo / sabendo que não se trata disso / sempre não se trata disso (Tradução nossa).

${ }^{3}$ [...] cada palavra diz o que diz e além disso mais e outra coisa (Tradução nossa).
} 
também nos permitissem pronunciar essas palavras transparentes capazes de exaurir o que as coisas, nós e os outros somos. Palavras que sempre diriam o que dizem e sujeitos que sempre estariam certos de que quando falam sabem de que se trata.

Quando uma conversa na escola deixa ecoar os versos de Pizarnik, ela é invadida por uma inquietação, mas também por uma imensa potência. Falar, então, deixa de ser uma habilidade técnica a se aperfeiçoar ou uma série de rodeios para a confirmação do que achamos saber. $O$ tom das palavras muda porque elas deixam de estar obrigadas a buscar o modo certo, correto de agruparse (o modo certo de pensar) e podem entregar-se a um exercício muito mais vital. Matheus é um menino que mostra a potência que se abre quando alguém está disposto a entregar-se a essa dimensão vital da linguagem. Naquela oportunidade ele estava à procura não de palavras certas, mas de palavras verdadeiras que lhe permitissem dizer a intensidade dessa imagem que comtemplava no espelho. A dicotomia entre uma imagem que estaria viva e outra que estaria morta na qual estavam presos seus colegas não o conformava. Escutamos argumentos a favor de uma ou de outra. Matheus não se rendeu nem a uns nem aos outros: “Não, não, não! A imagem no espelho não está nem viva sem morta", repetia com veemência. Até que, depois de muito esforço e muita conversação, uma "alma sem coração", nem viva nem morta, irrompeu e nos deixou a todos à beira das palavras pronunciadas até esse momento, nos lançou para o limite do que conseguíamos pensar: "como assim nem viva nem morta?" “O que seria uma alma sem coração?"

Matheus não tinha lido Pizarnik, mas certamente suas palavras diziam o que diziam e além disso mais e outra coisa. E já "não se tratava disso", e a divisão certa entre o vivo e o morto nos abandonou, e nossas palavras se encontraram com a impossibilidade de continuar preenchendo tão levianamente nossas certezas e começaram a contorná-las e a perceber que um mundo se abria além delas, que um mundo as excedia.

Mas, como pensar esse algo a mais, esse excesso que portam palavras como as de Matheus? 


\section{a loucura, o murmúrio obstinado da linguagem}

O trabalho que realiza Michel Foucault (1997) de debruçar-se sobre o modo em que nossa cultura foi construindo toda uma gramática para delimitar e explicar a loucura pode ajudar a pensar nesse excesso da linguagem.

A partir da loucura, Foucault considera que esse algo a mais que albergam as palavras que constituem a linguagem de uma cultura (aquela que the permite nomear-se e, por tanto, pensar-se de uma determinada maneira) é uma espécie de fundo que possibilita e, ao mesmo tempo, ameaça a constituição do que poderíamos chamar de obra da história, da linguagem legitimada ou oficial de uma cultura.

A loucura é precisamente um espaço de desequilíbrio, de desestabilização dos sentidos que a linguagem instalada pretende capturar. O discurso médico, ao catalogar a loucura como doença mental, cumpre a função de manter-nos resguardados desse fundo caótico e ameaçador que ela é. Traça contornos claros e distintos a fim de exorcizar isso que o excede. Essa linha divisória coloca a história, a ciência, a cultura no seguro território da razão, das palavras lúcidas, e deixa para a loucura um espaço claramente separado, oposto, radicalmente outro.

Assim, de um lado, a linguagem da cultura possibilita uma experiência que seria fundamentalmente razão, obra, sentido, história e, do outro, algo que a excede que é experiência indiferenciada, trágica, desnuda. Esta última é capaz de questionar os limites da primeira. A loucura tem a ver com uma espécie de excesso da experiência (ou da linguagem, poderíamos dizer aqui) ao mesmo tempo em que possibilita esse limite.

No prefácio de A história da loucura..., Foucault (1999a) vai nomear a loucura como "ausência de obra", como uma dimensão que permanece inalterada enquanto a história e seu trabalho oficial com as palavras constroem sua obra. A loucura seria assim um fundo de sem-sentido, uma ausência de sentido (de obra) a partir do qual o sentido das palavras que nomeiam nosso vínculo com o mundo se estabelece, embora sempre permaneça inaccessível a ele e, por isto, o ameace radicalmente. 


\begin{abstract}
A grande obra da história do mundo é indelevelmente acompanhada de uma ausência de obra, que se renova a cada instante, mas que corre inalterada em seu inevitável vazio ao longo da história; e desde antes da história, uma vez que ela já lá está na decisão primitiva, e ainda depois dela, uma vez que ela triunfará na última palavra pronunciada pela história. A plenitude da história só é possível no espaço vazio e povoado ao mesmo tempo, de todas as palavras sem linguagem que fazem ouvir, a quem afinar a orelha, um barulho surdo debaixo da história, o murmúrio obstinado de uma linguagem que falaria sozinha - sem sujeito falante e sem interlocutor, comprimida sobre ela própria, atada à garganta, desmoronando antes de ter atingido qualquer formulação e retornando sem brilho ao silêncio do qual jamais se desfez. Raiz calcinada do sentido (FOUCAULT, 1999a, p. 144).
\end{abstract}

Há algo que excede a linguagem, algo que escapa a ela e, ao mesmo tempo, a constitui. É palavra sem linguagem, barulho surdo, murmúrio obstinado, desmoronamento antes de ser formulação, raiz calcinada de sentido. É um "desobrar" que carcome a obra, mas a partir do qual a obra da história, das palavras oficiais, se constitui.

Existe um paradoxo: este fundo é, por definição, inominável e, no entanto, parece possível, para quem afina a orelha, ter algum tipo de experiência dele, experiência que ofereceria a possibilidade de transgressão dos limites da própria razão, da própria linguagem. Tendo presente que essa percepção que tenta compreender a loucura em seu estado selvagem é própria de um mundo que já a capturou, se dá um jogo entre o limite da experiência ou da linguagem como obra e a possibilidade de fazer experiência desse limite, de transgredi-lo. Esse é o exercício que Foucault pretende fazer ao embarcar-se nesse esforço por "esticar a orelha, debruçar-se sobre esse rosnar do mundo, tratar de aperceber tantas imagens que jamais foram poesia, tantos fantasmas que jamais alcançaram as cores da vigília" (FOUCAULT, 1999a, p. 145).

O esforço de Foucault é inspirador para pensar o sentido de nossas conversações na escola. Ele convida a trabalhar não sobre o aperfeiçoamento de uma linguagem que é obra, sobre a consolidação ou desenvolvimento de habilidades que estabilizam uma gramática instalada. Ele convida a afinar o ouvido, a debruçar-se sobre os limites da linguagem que define o que é possível pensar para nós, que delimita nossa experiência. Esse esforço é um esforço 
transgressor das palavras. É um esforço que se dirige para aquilo que as palavras dizem "a mais" ou para aquilo do que "não se trata", em termos de Pizarnik.

\section{a literatura, um espaço de hesitação da linguagem}

Esse exercício de perceber essas "imagens que jamais foram poesia" pode ser considerado um esforço poético, um esforço para entrar em contato com essa dimensão da linguagem onde loucura e poesia, de algum modo, se encontram.

Em textos posteriores a A história da loucura... (1997), o filósofo explorará a literatura como possibilidade de transgressão das fronteiras da experiência histórica. A literatura compartilha com a loucura aquela capacidade de ameaça à obra da razão e da história que define os limites dentro dos quais se configura a experiência, o que pode ser dito e pensado em uma cultura.

A loucura quebra a obra da razão, excede seu limite, e se situa na cara exterior desse limite. Do mesmo modo, a literatura questiona a própria obra dentro da qual se conforma como literatura. É um instaurar-se que questiona a obra, que força seus limites sem, ao mesmo tempo, poder deixar de ser obra.

Tanto a loucura quanto a obra são linguagem. Mas,

[...] enquanto a obra é uma linguagem da razão, plena de sentido, que obedece a um código [...], a loucura é insensatez, desrazão, não-sentido, vazio de sentido, linguagem que transgrede as leis da linguagem, a ponto de ser considerada não-linguagem, ou, para empregar termos que acompanharão toda a reflexão de Foucault sobre a linguagem, é 'murmúrio', 'ruído', 'rumor' (MACHADO, 2001, p. 42).

A literatura se coloca em tensão com o discurso ao sinalizar o vazio que este tenta disfarçar, preencher com suas palavras. Este último está do lado da história. A discursividade é a configuração da linguagem como obra que se detém em si própria e ganha uma certa densidade que dá corpo às palavras. A literatura, como um modo especial de condensação da linguagem de uma outra natureza, se coloca em tensão com a obra e tem a possibilidade de mexer com essa positividade discursiva instalada pela obra, de ameaçá-la ao arruinar a obra da linguagem. Ao deixar suspendida essa obra da linguagem, ao impossibilitar seguir dizendo da mesma forma a ordem estabelecida, interfere nessa relação do enunciado com a linguagem e não permite continuar a dizer da mesma forma por tornar móvel, 
desde dentro da própria da obra, aquilo que o discurso fixou. (Impossível não pensar na potência poética da "alma sem coração" de Matheus que nos deparou com essa impossibilidade).

Blanchot reafirma a capacidade paradoxal da literatura para arruinar a obra que ela mesma constitui. $\mathrm{O}$ trabalho da literatura não está do lado da história. Não está em utilizar as palavras usuais com mais maestria, não está no aperfeiçoamento da linguagem corrente. Está na abordagem daquele ponto

[...] em que falar não é mais do que a sombra da fala, linguagem que ainda não é mais do que sua imagem, linguagem imaginária e linguagem do imaginário, aquela que ninguém fala, murmúrio do incessante e do interminável a que é preciso impor silêncio, se se quiser, enfim, que se faça ouvir (BLANCHOT, 1987, p. 42).

Na conferência "Linguagem e literatura", Foucault (2001) faz uma distinção entre a linguagem, a obra e a literatura. A linguagem estaria composta tanto pelo código, o sistema que permite a compreensão entre os que falam, quanto pelo conjunto de tudo o que foi dito, "o murmúrio de tudo o que é pronunciado" (FOUCAULT, 2001, p. 140). A obra, seria a estabilização desse murmúrio dentro de uma configuração que lhe confere uma certa densidade que é enigmática. Finalmente, é a literatura, que não é nem obra nem linguagem, que desenha um outro espaço exterior e vazio.

A literatura é uma distância aberta no interior da linguagem, uma distância incessantemente percorrida e jamais coberta; uma espécie de linguagem que oscila sobre si mesma, uma espécie de vibração imóvel. $\mathrm{Na}$ verdade, oscilação e vibração são palavras insuficientes e inadequadas porque sugerem dois polos: a literatura seria, ao mesmo tempo, literatura mas, também, linguagem e haveria entre a literatura e a linguagem como que uma hesitação (FOUCAULT, 2001, p. 142).

\section{a literatura, um excedente mudo da linguagem}

Na entrevista intitulada "A loucura, a ausência da obra" (1999b), falando sobre os interditos da linguagem e suas possibilidades de transgressão, Foucault assinala que a literatura (e suas possibilidades transgressoras),

[...] consiste em submeter uma palavra, aparentemente conforme ao código reconhecido, a um outro código cuja chave é dada nesta palavra mesma; de tal forma que esta é desdobrada no interior de si: ela diz o que ela diz, mas ela acrescenta um excedente mudo que enuncia silenciosamente o que ela o diz e o código segundo o qual ela diz. Não se trata aqui de uma linguagem cifrada, mas de uma linguagem 
estruturalmente esotérica. Quer dizer: ela não comunica, ao escondê-la, uma significação interdita; ela se instala, para começo de jogo, em uma dobra essencial da palavra. Dobra que a escava do interior e, talvez, até o infinito [...]. É essa liberação obscura e central da palavra no coração dela própria, sua fuga incontrolável para uma moradia sempre sem luz, que nenhuma cultura pode aceitar imediatamente. Não é em seu sentido, não em sua matéria verbal, mas em seu jogo é que uma tal palavra é transgressiva (FOUCAULT, 1999b, p. 194, grifo do autor).

Nesta entrevista, Foucault analisa a loucura, a partir da psicanálise, como um tipo de linguagem. Uma linguagem especial que, ao mesmo tempo em que é incompatível com a obra, é a zona de onde a obra provém. A partir de Freud a loucura é uma palavra que se envolve a si própria. Por baixo do que ela diz, ela diz outra coisa. Literatura e loucura se aproximam porque as duas são autoreferência vazia (Cf. MACHADO, 2001).

Este tipo de linguagem redobrada encerra em si mesma a chave de seu próprio deciframento. Foucault vê na literatura o poder que a linguagem possui de ir além de si, para levar-nos além da experiência na qual definimos aquilo que somos, para permitir-nos trabalhar sobre a zona que excede os limites do que é possível dizer e pensar dentro da obra da história.

Como assinala Larrosa (1995), a linguagem literária nos mantém em uma permanente expectativa, porque a próxima palavra a ser pronunciada pode provocar o desabamento de tudo aquilo que até esse momento as próprias palavras, cuidadosa e prolixamente ordenadas, vinham construindo. A literatura compromete a linguagem em um duplo sentido: tanto como código quanto como arquivo de todo o dito. Mas, como esclarece Foucault (2001), esse comprometimento não acontece por desafiar as leis próprias do código linguístico nem pela pronuncia de palavras que, ainda dentro do código, tem proibida sua articulação, nem por colocar enunciados perfeitamente legíveis pelo código, mas que portam significações censuradas, proibidas.

Foucault pode nos ajudar a pensar nessas frases inesperadas e, ao mesmo tempo, buscadas que ouvimos das crianças na escola. Frases como as de Matheus obrigam a parar a conversação. Elas não desafiam as leis do código linguístico, também não pronunciam palavras proibidas. Essas frases são perfeitamente legíveis. No entanto, ao mesmo tempo, produzem a sensação de que há nessas 
palavras algo que se dobra e que se volta sobre o dicionário e sobre a gramática com que nomeamos o mundo. Valendo-se das palavras desse dicionário, esse espelho "nem vivo nem morto", essa "alma sem coração" o questionam, o negam, se surpreendem pelo modo em que ele ordena seus verbetes, o forçam a pensar-se. Frases como a de Matheus abrem para a prática da filosofia a possibilidade de trabalhar sobre esse território "estruturalmente esotérico", sobre esse "excedente mudo", sobre a "dobra das palavras" a fim de que a linguagem, a partir da qual constituímos o que somos, possa abrir-nos outras possibilidades de pensar-nos e pensar o mundo. Quando frases como essa são pronunciadas, nos surpreendem, mas, ao mesmo tempo, nosso trabalho pode ser pensado como uma busca delas.

Uma busca não dos temas que tratam, mas dessa zona onde a linguagem nos revela que "nunca se trata disso" (como dizia Pizarnik), que há nela uma sombra que a acompanha e que quando se faz presente faz cambalear o esforço das palavras por estabilizar o sentido e obriga a parar e a ter que pensar tudo de novo.

\section{buscar uma frase, não ceder nada à linguagem ${ }^{4}$}

Pierre Alféri (2006) ajuda a continuar explorando a singularidade do espaço onde pensamento e linguagem se encontram a partir do momento em que as palavras "dizem o que dizem e além disso mais e outra coisa" (PIZARNIK, 2000, p. 283). Encontramos no autor uma sintonia com as ideias de Foucault. O escritor vai pensar essa distância que se abre ao interior da linguagem em termos de “frase". É nas "frases possíveis" onde o pensamento se faz presente, diz.

Alféri nos lembra de que a língua é muito mais do que o conjunto das frases já formadas (o arquivo, poderíamos dizer, emulando a Foucault). Há na linguagem algo que excede a esse conjunto do já pronunciado. É precisamente ali onde se aloja o pensamento. O pensamento está em estrita relação com essa zona em que as palavras passam a ser um "avanço que a linguagem adquire sobre si

\footnotetext{
${ }^{4}$ Uma primeira exploração do texto de Alféri foi publicada em: OLARIETA, B. F. Uma frase possível... Revista Sul-Americana de Filosofia e Educação. n. 23 nov/2014-abr/2015, p. 1-3. Disponível em: http://www.periodicos.unb.br/index.php/resafe/article/view/16134/11465
} 
mesma" (ALFÉRI, 2006, p. 49). Alféri (2006) chama essa zona de avanço de "linguagem possível".

Buscar uma frase (2006), assim intitula seu livro. Essa é a tarefa de um escritor e de um pensador: buscar uma frase. Esses termos ecoam no sentido do nosso trabalho de filosofar na escola. Vejamos.

Uma frase é, basicamente, um "gesto instaurador de uma frase possível", sustenta Alféri. E o pensar supõe o entregar-se à tarefa de "buscar uma frase". No momento de invenção (em que uma frase se faz possível), o pensamento encontra seu lugar, afirma o autor. No momento em que uma "alma sem coração" encontra seu lugar, o pensamento encontra seu lugar, nós podemos afirmar.

Buscar que uma frase irrompa, que a linguagem que habitualmente é usada para expressar, para transmitir, para representar, para comunicar, etc., permita acessar a essa zona onde se vê excedida e deixa de dizer coisas: se torna, como diz Alféri, um "gesto instaurador".

Foucault (1984) dizia que a filosofia consiste em fazer uma experiência de si no pensamento. Alféri sustenta que a frase é uma experiência. "Fazer uma experiência, levá-la a seu término, é dizê-la" (ALFÉRI, 2006, p. 37). Portanto, conversar nos abre a possibilidade da experiência, a possibilidade de pensar a partir da exploração dos limites de nossa linguagem.

Só se pode buscar uma frase, uma linguagem possível, por meio de outras frases gastas (essas que compõem a linguagem da história, da obra, do discurso, nos termos de Foucault). Uma frase se faz possível quando essas frases gastas, de repente, parecem inutilizáveis. "Uma frase nova se inventa a partir do que se afasta, em uma distância e um vazio artificiais" (ALFÉRI, 2006, p. 51). É nesse momento concreto de invenção que "um pensamento tem seu lugar" (ALFÉRI, 2006, p. 51).

Buscar uma frase é entregar-se à tarefa de abrir um lugar para que o pensamento aconteça a partir de uma espécie de distanciamento do conjunto das frases já pronunciadas, mas, ao mesmo tempo, a partir delas. 
Buscar uma frase e quando ela apareça não soltá-la, tampouco manipulá-la, deixar que ela faça efeito, que nos pegue por surpresa, que diga algo a mais, que nos faça saber que "não se tratará disso" e nos obrigue a pensar.

Uma desordem sucede à instauração de uma frase, afirma Alféri, e comina a não deixar escapar nada. Essa é a exigência básica para que uma frase seja possível. Nessa exigência não deve ceder-se nada à linguagem instalada, aos dicionários que traçam os muros de nossa experiência. “A verdadeira fidelidade à linguagem não cede nada à linguagem", diz Alféri (2006, p. 56). A verdadeira fidelidade se entrega ao seu excesso, poderíamos dizer aqui.

Conversar, conversar, conversar até que as palavras se esgotem e se cansem de dizer o que dizem, até que cambaleiem, até que comecem a confundir-se, a não entender-se claramente, até que uma "alma sem coração" irrompa e não se deixe pensar muito claramente. E deixe em evidência que não se trata do espelho, não se trata do que está vivo ou do que está morto, que nunca se trata disso.

Enquanto conversamos buscamos essas frases, ou melhor, as esperamos. Às vezes essa espera é em vão; dizemos muito, mas a frase não aparece. Às vezes uma frase se faz possível e a deixamos passar sem dar-nos conta, quase sem percebê-la. Às vezes só nos deixa em silêncio, sem palavras, e põe em evidência que o que diz está nesse "excesso da linguagem" que ela porta.

Abrir um tempo e um espaço na escola para inclinar-nos, para estender-nos, para deixar-nos levar por frases possíveis como a de Matheus nos concede a oportunidade de deixar que as palavras assomem ao limite do que conseguem dizer e nos permitam dizer o que dizem e, além disso, mais e outra coisa... Ou, o que é o mesmo, que nos permitam começar a pensar.

\section{referências}

ALFÉRI, Pierre. Buscar uma frase. Buenos Aires: Amorrortu, 2006.

BLANCHOT, Maurice. O espaço literário. Rio de Janeiro: Rocco, 1987.

FOUCAULT, Michel. História da sexualidade 2. O uso dos prazeres. Rio de Janeiro: Graal, 1984.

FOUCAULT, Michel. A história da loucura na Idade Clássica. 5. ed. São Paulo: Perspectiva,1997. 
FOUCAULT, Michel. “Prefácio (Folie et déraison)”. In: FOUCAULT, M. Ditos E Escritos I. A problematização do sujeito: psicologia, psiquiatria e psicanálise. Rio de Janeiro: Forense Universitária, 1999a.

FOUCAULT, Michel. “A loucura, a ausência da obra”. In: FOUCAULT, M. Ditos $\mathcal{E}$ Escritos I. A problematização do sujeito: psicologia, psiquiatria e psicanálise. Rio de Janeiro: Forense Universitária, 1999b.

FOUCAULT, Michel. "Linguagem e literatura”. In: MACHADO, Roberto. Foucault, a filosofia e a literatura. 2. ed. Rio de Janeiro: Jorge Zahar Editor, 2001.

LARROSA, Jorge. La experiencia de la lectura. Estudios sobre literatura y formación.

Laertes, 1995.

LARROSA, Jorge. "Uma língua para a conversação". In: LARROSA, J. Tremores. Escritos sobre experiência. Belo Horizonte: Autêntica, 2015.

MACHADO, Roberto. Foucault, a filosofia e a literatura. $2^{\circ}$ ed. Rio de Janeiro: Jorge

Zahar Editor, 2001.

PIZARNIK, Alejandra. Poesía completa. Buenos Aires: Lumen, 2000.

recebido em: 17.12 .2016

aceito em: 20.01.2017 